\title{
Analisis Suhu Pada Analyzer Inkubator Bayi Berbasis Formula Mean
}

\author{
Kholid Al Sulaimi ${ }^{1}$, Wisnu Kartika*2, Iswanto ${ }^{3}$, Kuat Supriyadi ${ }^{4}$ \\ Universitas Muhammadiyah Yogyakarta, Indonesia
}

INFO ARTIKEL

Alamat Web Artikel:

Journal.umy.ac.id/index.php/

$\mathrm{mt} /$ article/view/7255

DOI:

https://doi.org/10.18196/mt.010101

Data Artikel:

Diterima:

19 Okt 2019

Direview:

21 Okt 2019

Direvisi:

24 Okt 2019

Disetujui:

31 Okt 2019

Korespondensi:

wisnu2007@umy.ac.id

\begin{abstract}
ABSTRAK
Baby inkubator adalah alat untuk menjaga stabilitas suhu bayi prematur. Suhu adalah salah satu parameter penting. Oleh karena itu, kestabilannya harus dipantau berdasarkan standar yang disyaratkan oleh BPFK (Pusat Keselamatan Fasilitas Kesehatan) sehingga diperlukan kalibrasi. Tujuan penelitian ini membuat alat kalibrasi untuk parameter suhu inkubator bayi dengan empat titik pengukuran. Sensor utama dari parameter suhu penganalisis inkubator adalah LM35 sebagai sensor suhu T1, T2, T3, dan T4. Kisaran suhu yang dapat dideteksi adalah antara $20,00{ }^{\circ} \mathrm{C}-50,00{ }^{\circ} \mathrm{C}$. Suhu di dalam inkubator bayi harus diantara $35,5{ }^{\circ} \mathrm{C}-37{ }^{\circ} \mathrm{C}$. Pengujian ini dilakukan pada inkubator bayi mulai dari suhu $32{ }^{\circ} \mathrm{C}-37^{\circ} \mathrm{C}$. Data dikumpulkan dari nilai titik uji pada setiap titik suhu, perbandingan suhu antara modul menggunakan pengukur suhu sebagai alat pembanding dan kalibrasi inkubator bayi. Daya output untuk sensor suhu LM35 dilakukan sebanyak \pm 5 kali. Nilai kesalahan terbesar ditemukan pada sensor suhu T4 pada $\pm 1,09762824 \%$ dan pada suhu $37{ }^{\circ} \mathrm{C}$, sedangkan nilai kesalahan terkecil ditemukan pada sensor suhu T1 pada $\pm 0,005633803 \%$ pada suhu $35^{\circ} \mathrm{C}$. Pengukuran kalibrasi suhu inkubator bayi menunjukkan margin meter suhu inkubator bayi $\pm 1{ }^{\circ} \mathrm{C}$ pada pengaturan suhu $32{ }^{\circ} \mathrm{C}, 33^{\circ} \mathrm{C}$, dan $34^{\circ} \mathrm{C}$.
\end{abstract}

Kata Kunci: Baby Incubator, Incubator Analyzer, Suhu

\section{PENDAHULUAN}

Bayi prematur adalah bayi yang lahir antara usia kehamilan 34 sampai 36 minggu. Bayi prematur yang lahir di bawah 32 - 34 minggu akan mempunyai penampilan fisik yang khas, yaitu kulit lebih tipis dan gambaran pembuluh darahnya dapat terlihat. Bayi prematur belum bisa beradaptasi terhadap suhu disekitarnya, bayi tersebut harus segera dimasukkan ke dalam tempat khusus yaitu inkubator bayi untuk menghangatkan bayi tersebut agar dapat berkembang dengan baik karena seorang bayi prematur membutuhkan suhu yang sesuai seperti saat berada di dalam kandungan, yaitu antara $35,5^{\circ} \mathrm{C}-37^{\circ} \mathrm{C}[1]$.

Inkubator bayi berfungsi menjaga kestabilan suhu tubuh pada bayi prematur. Inkubator bayi memiliki beberapa parameter yaitu temperatur, kelembaban, air flow dan noise. Suhu dalam inkubator bayi antara 35,5oC-37oC, dengan tingkat kebocoran suhu luar $\pm 1{ }^{\circ} \mathrm{C}$, tingkat kelembaban antara $\geq 70 \%$, laju aliran udara $<0,35 \mathrm{~ms}$, dan tingkat kebisingan di dalam inkubator $<60 \mathrm{dBA}$ [2]. Suhu berperan menjaga kestabilan suhu bayi, keakuratan suhu harus sesuai yang telah ditetapkan oleh BPFK (Balai Pengamanan Fasilitas Kesehatan). Suhu dalam inkubator bayi yang terlalu rendah akan menyebabkan bayi mengalami cedera kedinginan (hipotermia), sebaliknya bila suhunya tinggi dapat menyebabkan bayi mengalami apnea. Apnea yaitu berhenti bernapas sementara yang berlangsung lebih dari 20 detik dan dapat disertai penurunan frekuensi denyut jantung.

Kalibrasi alat kesehatan menjamin tersedianya alat yang sesuai standar pelayanan, persyaratan mutu, keamanan, manfaat, keselamatan, dan laik pakai di fasilitas pelayanan kesehatan dan fasilitas kesehatan lainnya dan meningkatkan akuntabilitas, dan mutu pelayanan balai pengujian fasilitas kesehatan dan institusi pengujian fasilitas kesehatan dalam pengujian dan/atau kalibrasi alat kesehatan [3]. Untuk melakukan kalibrasi alat inkubator bayi diperlukan alat Incubator analyzer. 


\section{Sulaimi, Kartika, Iswanto, Supriyadi}

Analisis Suhu Pada Analyzer Inkubator Bayi

Incubator analyzer merupakan alat untuk memverifikasi pengoperasian dan kondisi ruangan inkubator bayi yang dapat melakukan perekaman kesesuaian parameter dalam inkubator bayi seperti aliran udara, kebisingan, suhu (dengan 4 mode pengukuran individual), dan kelembaban relatif [4].

\section{METODE PENELITIAN}

Metode yang dilakukan dalam penelitian ini terdiri dari beberapa tahap, yaitu: perancangan hardware, perancangan software, pengujian alat, dan pengambilan data.

\subsection{Perancangan Hardware}

Perancangan hardware pada modul menggunakan beberapa rangkaian diantaranya adalah rangkaian system minimum microcontroller ATMega 328p, rangkaian sensor suhu LM35, rangkaian penguat non-inverting amplifier, rangkaian LCD, modul step up dan modul charger, baterai 3,7 V.

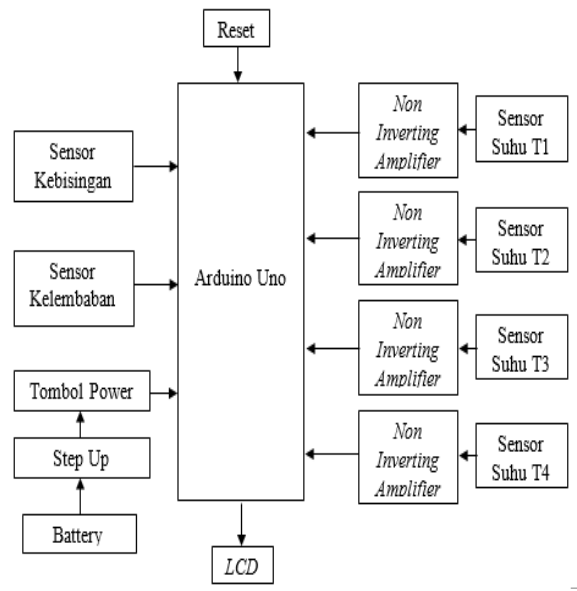

Gambar 1 Diagram Blok Sistem

Ketika tombol power ditekan, maka sensor suhu T1, T2, T3, T4 akan aktif dan akan memulai pembacaan suhu. Data hasil pembacaan kemudian masuk ke rangkaian non-inverting amplifier untuk menguatkan tegangan output dari sensor suhu LM35, kemudian masuk ke port ADC pada Arduino Uno, hasil (output) yang ditampilkan dalam satu LCD secara bersamaan. Apabila akan melakukan pengukuran dari awal atau mengulang pengukuran, maka dapat dilakukan dengan menekan tombol reset.

\subsection{Perancangan Software}

Perancangan software untuk mengolah tegangan output sensor suhu LM35 menjadi suhu dalam Celcius menggunakan pemrograman Arduino. Diagram alir proses dapat dilihat pada Gambar 2.2

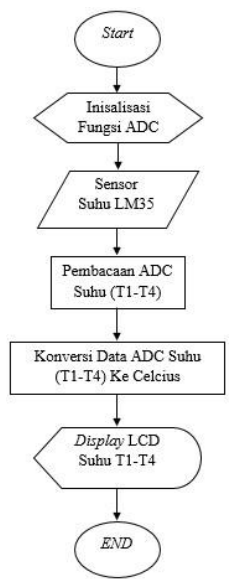

Gambar 2 Diagram Alir Proses

Medika Teknika : Jurnal Teknik Elektromedik Indonesia, Vol 01 No. 1, Oktober $2019 \mid 2$ 
Sulaimi, Kartika, Iswanto, Supriyadi

Analisis Suhu Pada Analyzer Inkubator Bayi

\section{HASIL DAN PEMBAHASAN}

Pada penelitian ini, melakukan pengukuran test point, perbandingan modul dengan pembanding (Temperature Meter), dan kalibrasi pada inkubator bayi.

\subsection{Pengukuran Test Point}

Tabel 1 Test Point Suhu T1

\begin{tabular}{|c|c|c|c|}
\hline \multicolumn{4}{|c|}{ Test Point T1 } \\
\hline Setting & Suhu T1 & TP 1 & TP 2 \\
\hline 32 & 32.17 & 0.322 & 2.078 \\
\hline 33 & 33.439 & 0.333 & 2.150 \\
\hline 34 & 34.581 & 0.343 & 2.223 \\
\hline 35 & 35.502 & 0.352 & 2.277 \\
\hline 36 & 36.426 & 0.360 & 2.313 \\
\hline 37 & 37.55 & 0.368 & 2.409 \\
\hline
\end{tabular}

Tabel 2 Test Point Suhu T2

\begin{tabular}{|c|c|c|c|}
\hline \multicolumn{4}{|c|}{ Test Point T2 } \\
\hline Setting & Suhu T2 & TP 1 & TP 2 \\
\hline 32 & 32.66 & 0.3272 & 2.1579 \\
\hline 33 & 33.585 & 0.337 & 2.2162 \\
\hline 34 & 34.822 & 0.349 & 2.284 \\
\hline 35 & 35.726 & 0.353 & 2.322 \\
\hline 36 & 36.548 & 0.364 & 2.385 \\
\hline 37 & 37.16 & 0.376 & 2.457 \\
\hline
\end{tabular}

Tabel 3 Test Point Suhu T3

\begin{tabular}{|c|c|c|c|}
\hline \multicolumn{4}{|c|}{ Test Point T3 } \\
\hline Setting & Suhu T3 & TP 1 & TP 2 \\
\hline 32 & 32.173 & 0.325 & 2.073 \\
\hline 33 & 33.493 & 0.337 & 2.164 \\
\hline 34 & 34.654 & 0.350 & 2.228 \\
\hline 35 & 35.209 & 0.352 & 2.259 \\
\hline 36 & 36.348 & 0.361 & 2.317 \\
\hline 37 & 37.37 & 0.363 & 2.326 \\
\hline
\end{tabular}

Tabel 4 Test Point Suhu T4

\begin{tabular}{|c|c|c|c|}
\hline \multicolumn{4}{|c|}{ Test Point T4 } \\
\hline Setting & Suhu T4 & TP 1 & TP 2 \\
\hline 32 & 30.05 & 0.3072 & 2.015 \\
\hline 33 & 31.793 & 0.314 & 2.016 \\
\hline 34 & 32.601 & 0.327 & 2.094 \\
\hline 35 & 34.146 & 0.344 & 2.232 \\
\hline 36 & 35.244 & 0.356 & 2.332 \\
\hline 37 & 36.66 & 0.361 & 2.338 \\
\hline
\end{tabular}

Semakin tinggi suhu ruang inkubator bayi, maka akan semakin tinggi juga nilai pengukuran suhu. Kenaikan suhu pada pengukuran suhu ruang inkubator bayi berpengaruh terhadap kenaikan tegangan output pada sensor suhu LM35. Kenaikan tegangan output LM35 TP 1 merupakan output

Medika Teknika : Jurnal Teknik Elektromedik Indonesia, Vol 01 No. 1, Oktober 2019|3 


\section{Sulaimi, Kartika, Iswanto, Supriyadi}

Analisis Suhu Pada Analyzer Inkubator Bayi

tegangan sebelum dikuatkan dan TP 2 merupakan output tegangan setelah dikuatkan. Penguatan menggunakan non-inverting amplifier dengan penguatan \pm 6 kali.

\subsection{Pengukuran Terhadap Kalibator}

Tabel 5 Perbandingan Suhu T1

\begin{tabular}{|c|c|c|}
\hline \multicolumn{3}{|c|}{ Sensor Suhu T1 } \\
\hline Setting & LCD & $\begin{array}{c}\text { Temperature } \\
\text { Meter }\end{array}$ \\
\hline 32 & 32.17 & 32.3 \\
\hline 33 & 33.44 & 33.4 \\
\hline 34 & 34.58 & 34.5 \\
\hline 35 & 35.50 & 35.5 \\
\hline 36 & 36.43 & 36.3 \\
\hline 37 & 37.55 & 37.4 \\
\hline
\end{tabular}

Tabel 6 Perbandingan Suhu T2

\begin{tabular}{|c|c|c|}
\hline \multicolumn{3}{|c|}{ Sensor Suhu T2 } \\
\hline Setting & LCD & $\begin{array}{c}\text { Temperature } \\
\text { Meter }\end{array}$ \\
\hline 32 & 32.66 & 32.7 \\
\hline 33 & 33.59 & 33.8 \\
\hline 34 & 34.82 & 34.8 \\
\hline 35 & 35.73 & 35.7 \\
\hline 36 & 36.55 & 36.5 \\
\hline 37 & 37.16 & 37.2 \\
\hline
\end{tabular}

Tabel 7 Perbandingan Suhu T3

\begin{tabular}{|c|c|c|}
\hline \multicolumn{3}{|c|}{ Sensor Suhu T3 } \\
\hline Setting & LCD & $\begin{array}{c}\text { Temperature } \\
\text { Meter }\end{array}$ \\
\hline 32 & 32.17 & 32.2 \\
\hline 33 & 33.49 & 33.6 \\
\hline 34 & 34.65 & 34.6 \\
\hline 35 & 35.21 & 35.0 \\
\hline 36 & 36.35 & 36.1 \\
\hline 37 & 37.37 & 37.2 \\
\hline
\end{tabular}

Tabel 8 Perbandingan Suhu T4

\begin{tabular}{|c|c|c|}
\hline \multicolumn{3}{|c|}{ Sensor Suhu T4 } \\
\hline Setting & LCD & $\begin{array}{c}\text { Temperature } \\
\text { Meter }\end{array}$ \\
\hline 32 & 30.05 & 30.3 \\
\hline 33 & 31.79 & 31.6 \\
\hline 34 & 32.6 & 32.9 \\
\hline 35 & 34.15 & 33.9 \\
\hline 36 & 35.24 & 34.9 \\
\hline 37 & 36.66 & 36.3 \\
\hline
\end{tabular}

Semakin tinggi suhu ruang inkubator bayi, maka akan semakin tinggi juga nilai pengukuran suhu. Kenaikan suhu pada display LCD mendekati kenaikan suhu pada alat pembanding. Perbedaan suhu rata-rata pada display LCD dengan alat pembanding (Temperature Meter) tidak lebih dari $1^{\circ} \mathrm{C}$.

Medika Teknika : Jurnal Teknik Elektromedik Indonesia, Vol 01 No. 1, Oktober 2019 | 4 


\subsection{Pembahasan Rangkaian}

\subsubsection{Rangkaian Supply Baterai}

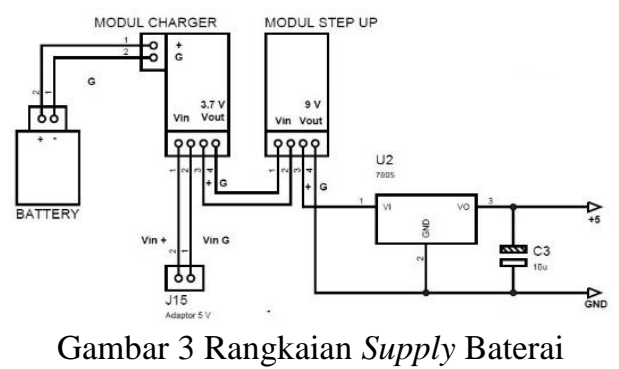

Rangkaian supply baterai berfungsi untuk memberikan tegangan pada seluruh rangkaian, dimana baterai yang digunakan adalah jenis baterai lithium atau baterai yang biasa digunakan pada ponsel. Tegangan dari baterai berkisar 3,7 V. Modul charger untuk melakukan pengisian daya baterai, yang dilengkapi dengan over-load protection yang aman bagi modul ketika dilakukan pengisian daya baterai. Tegangan baterai dinaikan menjadi $9 \mathrm{~V}$, dengan modul step up. Output tegangan baterai $9 \mathrm{~V}$ diturunkan kembali menggunakan IC Regulator 7805 yang menjadikan tegangan baterai menjadi $5 \mathrm{~V}$, dikarenakan seluruh rangkaian modul membutuhkan tegangan maksimal $5 \mathrm{~V}$.

\subsubsection{Rangkaian Non-Inverting}

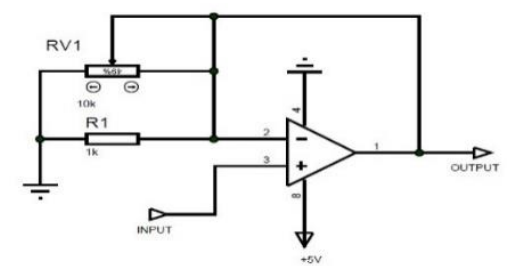

Gambar 4 Rangkaian Non-Inverting

Saat sensor suhu LM35 mendeteksi suhu ruangan, perubahan tegangan output yang dihasilkan masih kecil, dimana perubahannya hanya sekitar $0,01 \mathrm{~V}$ setiap perubahan suhu. Perubahan nilai tegangan output sensor LM35 akan diperkuat oleh rangkaian non-inverting, dengan nilai penguatan sebesar 1 hingga 10 kali yang disesuaikan dengan kebutuhan tegangan referensi pada Arduino Uno yaitu $3,3 \mathrm{~V}$.

\subsubsection{Rangkaian LCD}

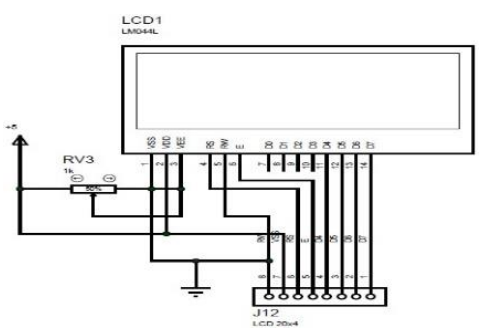

Gambar 5 Rangkaian LCD Karakter20x4

Blok rangkaian LCD menggunakan tampilan output berupa LCD karakter 20 x 4, dimana nantinya nilai ADC yang terbaca dalam bentuk nilai Celcius akan tertampil pada layar LCD. Untuk dapat menghidupkan LCD diperlukan tegangan $5 \mathrm{~V}$ pada pin VDD dan ground pada pin VSS dan

Medika Teknika : Jurnal Teknik Elektromedik Indonesia, Vol 01 No. 1, Oktober 2019|5 
untuk pengaturan kontras kecerahan LCD dipasang multiturn yang dirangkai seri dengan tegangan input $5 \mathrm{~V}$, untuk nilai resistornya menggunakan nilai $1 \mathrm{k} \Omega$ karena dengan nilai tersebut didapat kontras warna yang baik dan tidak terlalu cerah.

\subsubsection{Rangkaian Arduino Uno}

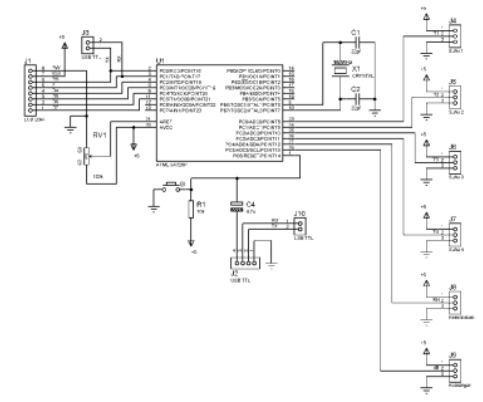

Gambar 6 Rangkaian Arduino Uno

Arduino uno berfungsi sebagai otak dan pengendali segala aktifitias dari alat. Arduino uno ini menggunakan ATMega 328P yang telah dilengkapi dengan ADC internal sehingga memudahkan sistem dalam konversi analog menjadi digital. Pada Arduino uno terdapat 6 port ADC, port untuk menyambungkan dengan LCD karakter, dan juga terdapat port ke USB TTL yang berfungsi untuk memasukkan program yang dibutuhkan modul.

\section{KESIMPULAN}

Dari hasil penelitian yang telah dilakukan didapat bahwa penguatan output sensor suhu LM35 dilakukan sebesar \pm 6 kali penguatan, dengan berpatokan tegangan referensi 3,3 V pada saat pembacaan maksimum yaitu $50,00{ }^{\circ} \mathrm{C}$. Penguatan output sensor suhu LM35 berpengaruh terhadap ketelitian perubahan kenaikan atau penurunan suhu pada penampilan display LCD. Dari hasil uji coba sensor suhu (LM35) modul, nilai yang dihasilkan cukup signifikan dengan alat pembanding Temperature Meter. Pada suhu modul didapat nilai rata-rata error dibawah 1,5\%, dimana error terbesar didapat pada sensor suhu T4 yaitu $\pm 1.09762824 \%$ dan pada suhu $37^{\circ} \mathrm{C}$. Nilai error terkecil didapat pada sensor suhu T1 yaitu $0.005633803 \%$ dan pada suhu $35^{\circ} \mathrm{C}$.

\section{DAFTAR PUSTAKA}

[1] A. M. Ridho, "Miniatur Pemantau Suhu Inkubator Berbasis Mikrokontroler Atmega 8535 dan Jaringan Nirkabel," Universitas Gunadarma, 2014.

[2] D. Catur, F. Adi Iskandarianto, and Ya'umar, "Optimalisasi Kelembaban Udara Pada Tabung Baby Incubator Melalui Integrasi Pengendalian Temperatur Dan Kelembaban," Institut Teknologi Sepuluh Nopember, 2007.

[3] Kemenkes RI, "Berita Negara RI No.1197:2015, Permenkes 54-2015 Pengujian dan Kalibrasi Alat kesehatan," p. 32, 2015.

[4] R. Ericka Helen, B. Guruh Irianto, and A. Pudji, "Incubator Analyzer Portabel Tampil PC Via Bluetooth," Poltekes Surabaya, p. 1, 2016. 